7 McKarness R. Not all in the mind. London : Pan, 1976.

8 Barr RG, Levine MD, Watkins JB. Recurrent abdominal pain of childhood due to lactose intolerance. A prospective study. $N$ Engl f Med $1979 ; 300$ :1449-52.

- Liebman WM. Recurrent abdominal pain in children: lactose and sucrose intolerance, a prospective study. Pediatrics 1979;64:43-5.

10 Soothill JF. Elimination diets in childhood. Br Med F 1980;280:401-2.

11 Rachman SJ, Philips C. Psychology and medicine. Harmondsworth: Penguin, 1978.

12 Atherton D, Sewell M, Soothill JF, Wells RS, Chivers C. A double-blind controlled crossover trial of an antigen-avoidance diet in atopic eczema. Lancet 1978 ; : $401-3$.

13 Apley J. The Child with abdominal pains. 2nd ed. Oxford: Blackwell, 1975.

14 Apley J, Hale B. Children with recurrent abdominal pain: how do they grow up ? Br Med F 1973; ;iii:7-9.

${ }^{15}$ Berger HG, Honig PJ, Liebman R. Recurrent abdominal pain: gaining control of the symptom. Am $\mathcal{F}$ Dis Child 1977;131:1340-4.

16 Hughes MC, Zimin R. Children with psychogenic abdominal pain and their families. Clin Pediat 1978;17:569-73.

17 Weller S. The patient is a family. World Medicine $1975 ; 10: 18-20$.

\section{Leber's optic neuropathy}

The study of hereditary optic neuropathy dates from Theodor Leber's paper published in 1871, though von Graefe had reported the condition in three brothers in 1858. Despite the relative rarity of Leber's disease some remarkably extensive pedigrees have been compiled. Young men are predominantly affected but transmission is by women, suggesting an $\mathrm{X}$-linked recessive inheritance. In many families, however, the hereditary pattern does not conform to conventional Mendelian principles. No affected man has transmitted either the carrier state or the disease, and symptomless female carriers transmit not only the disease to half or more of their sons but also the carrier state to most of their daughters. Moreover, $10-20 \%$ of female carriers $(30-40 \%$ in some Japanese families) may themselves manifest the disease. ${ }^{12}$

Fresh information has appeared recently ${ }^{3}$ about a family in Australia in which blindness due to Leber's disease was reported originally in 1921.4 This family has been traced back over 160 years to the marriage of a Chinese seaman to an Irish girl and now comprises 91 members in six generations, with 23 men and seven women affected. The onset was usually in the late teens or early twenties with a range of 5 to 49 years. Twins have been affected at the same age, ${ }^{5}$ but the variation in the age of onset suggests that an environmental factor may also contribute. ${ }^{6}$ Typically a young man develops acute or subacute failure of vision; deterioration takes place over days, weeks, or months, stopping short of complete blindness, and improvement is unusual. Both eyes may be affected simultaneously, or symptoms may develop in the second eye within a few days or months and almost invariably within a year. In two of the Australian patients, aged 42 and 19, only one eye had been affected after 12 and 14 years respectively.

The impaired vision, sometimes with sluggish pupillary responses, is usually associated with a bilateral central scotoma and sometimes with peripheral constriction of the visual fields. Optic atrophy starts in the papillomacular fibres, resulting in temporal pallor; later more extensive disc pallor develops, with a reduction in the number of small vessels crossing the disc margin and attenuation of retinal arterioles. In some cases the retinal vessels show a striking tortuosity. A further feature is defective colour vision, an acquired dyschromatopsia of the red-green axis. These findings have been considered diagnostic of Leber's optic neuropathy ${ }^{7}$ and should make invasive investigations unnecessary. If the family history does not confirm the diagnosis and if there is any doubt, other forms of optic neuropathy and particularly those due to compressing lesions must be considered. In the acute stage of Leber's optic neuropathy there is a fleeting papillitis with blurring of the disc margins, swelling and glistening of the nerve fibre layer around the disc, and irregular dilatation of the peripapillary capillaries without abnormal vascular permeability on fluorescein angiography. ${ }^{8}$ Pain in the eye aggravated by movement, which is a common presenting symptom in optic neuritis due to multiple sclerosis, has been reported in only a few cases of Leber's optic neuropathy, and transient visual blurring (Uhthoff's syndrome) is also rare. ${ }^{9}$ In a few families with Leber's optic neuropathy some members have had psychiatric and other neurological deficits of a diffuse type, ${ }^{610}$ including an encephalitic syndrome, ${ }^{11}$ and also disorders outside the nervous system.12 In many, however, optic neuropathy is the only manifestation.

According to one hypothesis Leber's optic neuropathy may be due to an inborn metabolic inability to detoxicate cyanide. Low plasma and urinary concentrations of thiocyanate have been found in some affected patients, ${ }^{210}$ and further support comes from the fact that smoking and urinary infections (both of which may lead to a rise in concentrations of cyanide) aggravate the condition. ${ }^{13}$ Nevertheless, neither treatment with hydroxycobalamin (which detoxicates cyanide) nor large doses of steroids has halted the failure of vision in the first affected eye nor prevented visual failure from developing in the second eye.?

At necropsy the few cases of Leber's disease studied ${ }^{13} 14$ have shown extensive axonal degeneration and loss of myelin in the central portion of the optic nerves. No case has been studied histologically in the early stage of the disease, and in view of the uncertain nature of the initial lesion in the optic nerve every opportunity should be taken to examine symptomless eyes in those at risk in families with the disease.

Visual evoked potentials have proved to be a sensitive index of optic nerve lesions in multiple sclerosis ${ }^{15}$ and other conditions, ${ }^{16}$ and have now been used to explore the unsolved problems in Leber's optic neuropathy. ${ }^{317}$ In advanced visual impairment the response appears to be absent. In patients with less severe lesions a marked reduction in amplitude with desynchronisation leading to a widened or bifid response is consistent with loss of nerve fibres with demyelination. In contrast to multiple sclerosis, sequential visual evoked responses deteriorate and there is no appreciable recovery of vision. Latencies have, however, been normal in symptomless eyes, even in those which later developed the disease, so that the technique is of no use as a screening test. Nevertheless, minor morphological abnormalities of the visual evoked responses were found in some symptomless males at risk and in some obligate and possible female carriers, with or without ophthalmic abnormalities.

Possibly in some cases identifying the carrier state or making a presymptomatic diagnosis would be feasible, though the absence of abnormalities in the visual evoked responses does not necessarily imply immunity. Asymptomatic abnormalities have been found in some descendants from male lineages, but these may represent separately inherited traits or partial forms of Leber's disease. We have to consider alternative, nonMendelian modes of vertical transmission, including mitochondrial inheritance, ${ }^{18}$ and cytoplasmic or transplacental transfer of an agent, possibly viral. ${ }^{19}$ Meanwhile both the aetiology and the mode of transmission of Leber's optic neuropathy remain a mystery. 
1 Bell J. Hereditary optic atrophy. In: Pearson K, ed. The treasury of human inheritance. London: Cambridge University Press, 1933; vol 2, part 4: 325-425.

2 Rogers JA. Leber's disease. Australian fournal of Ophthalmology 1977;5: 111-9.

s Carroll WM, Mastaglia FL. Leber's optic neuropathy: a clinical and visual evoked potential study of affected and asymptomatic members of a six generation family. Brain 1979;102:559-80.

4 Morlet C. Hereditary optic atrophy as a possible menace to the community. Med $\mathcal{F}$ Aust $1921 ; 11: 499-502$.

- King EF. Leber's disease in twins. Proc $R$ Soc Med 1939;32:763-4.

- Lees F, MacDonald AME, Turner JWA. Leber's disease with symptoms resembling disseminated sclerosis. F Neurol Neurosurg Psychiatry 1964; 27:415-21.

7 Nikoskelainen E, Sogg RL, Rosenthal AR, Friberg TR, Dorfman LJ. The early phase in Leber hereditary optic atrophy. Arch Ophthalmol 1977; 95:969-78.

8 Smith JL, Hoyt WF, Susac JO. Ocular fundus in acute Leber optic neuropathy. Arch Ophthalmol 1973;90:349-54.

- Perkin GD, Rose FC. Optic neuritis and its differential diagnosis. London: Oxford University Press, 1979.

10 Wilson J. Leber's hereditary optic atrophy: a possible defect of cyanide metabolism. Clinical Science 1965;29:505-15.

11 Wallace DC. A new manifestation of Leber's disease and a new explanation for the agency responsible for its unusual pattern of inheritance. Brain $1970 ; 93: 121-32$.

12 Wilson J. Skeletal abnormalities in Leber's hereditary optic atrophy. Ann Phys Med 1965;8:91-5.

13 Adams JH, Blackwood W, Wilson J. Further clinical and pathological observations in Leber's optic atrophy. Brain 1966;89:15-26.

14 Oud JSF, Henneman IP, Brugge RJ, et al. La maladie de Leber. Etude anatomique de deux cas dans une fratrie. $\mathcal{F}$ Neurol $S c i$ 1968;6:401-17.

15 Halliday AM, McDonald WI, Mushin J. Visual evoked potentials in patients with demyelinating disease. In: Desmedt JF, ed. Visual evoked potentials in man: new developments. London: Oxford University Press, 1976:438-49.

16 Halliday AM, Halliday E, Kriss A, McDonald WI, Mushin J. The patternevoked potential in compression of the anterior visual pathways. Brain 1976;99:357-74.

17 Dorfman LJ, Nikoskelainen E, Rosenthal AR, et al. Visual evoked potentials in Leber's hereditary optic neuropathy. Ann Neurol 1977;1:565-8.

18 Fine PEM. Mitochondrial inheritance and disease. Lancet 1978;ii :659-61.

19 Harper PS. Mendelian inheritance of transmissible agent ? The lesson of Kuru and the Australia antigen. $\mathcal{F}$ Med Genetics 1977;14:389-98.

\section{Spina bifida and the sex ratio}

Does the disturbed sex ratio often seen in spina bifida and anencephaly suggest that a gene on the $\mathrm{X}$ chromosome plays a part? For some years these conditions have been regarded as examples of "threshold defects" - that is, defects of multiple causation in which the inherited contribution is mediated by more than one gene and the number of genes required for the disease to develop varies according to the strength of the environmental factors. There is ample justification for this view. ${ }^{12} \mathrm{~A}$ recent article by Burn and Gibbens ${ }^{3}$ put forward the subsidiary hypothesis that in spina bifida the disturbance of the sex ratio (though not, as the title misleadingly suggests, the disease itself) may be related to an X-linked gene that interferes with the natural loss of affected fetuses. One strand of evidence they cite is the inverse correlation in the valleys of South Wales between the incidence of spina bifida and of spontaneous abortion. ${ }^{4}$

Certainly sex is important in the aetiology of spina bifida. In populations with a high risk of neural tube defects there is a pronounced excess of affected females, ${ }^{5}$ and when one case has occurred in a family there is a high risk of neural tube defects in the maternal half-sibs and in the mother's sisters' offspring. ${ }^{6}$ The risk is higher, too, in offspring of mixed marriages where the mother but not the father is from a higher-risk population-but not vice versa. ${ }^{7}$

Burn and Gibbens postulate that spontaneous abortion of fetuses with neural tube defects is inhibited by a mechanism at the deciduo-placental junction under the control of a single dominant mutant gene on the $\mathrm{X}$ chromosomes of mother or fetus or both. In this way there could be up to four copies of the mutant gene, the extreme case being a mother homozygous for the gene carrying a female fetus with two mutant genes. They argue that the more severe the defect, and thus the greater the number of these genes needed for survival (that is, to prevent miscarriage), the greater will be the proportion of females among survivors. An "epidemic" of all-female anencephalic infants would suggest a particularly severe form of malformationthe affected male fetuses having all been aborted, lacking the protection of four mutant genes.

Burn and Gibbens did not, however, test the application of their hypothesis to spina bifida by pedigree studies or animal experiments. Instead the authors set out a simple table of the expected proportions of offspring and parental genotypes for any X-linked gene if the system is in Hardy-Weinberg equilibrium, and illustrated it with a numerical example. Their calculations ignore the fact that if the hypothesis is correct a factor to represent the presumed selective advantage of the gene must be included in the equations. Goodness of fit to Hardy-Weinberg expectations based on genetic equilibrium in a population can on its own prove no hypothesis about mode of inheritance, and certainly in the present case there are far too many possible variables - gene frequencies, selection coefficients, genetic structure of the population-for any theory to be tested.

One of the oldest misconceptions in human genetics is to confuse X-linked inheritance with sex limitation and erroneously to implicate a gene on the $\mathrm{X}$ chromosome for conditions where females are more frequently affected than males. Classic examples of sex limitation are the short stature and lower digital ridge count in women. Hormonal and other. chemical differences between men and women may affect the threshold requirement for a trait not determined by the $\mathrm{X}$ chromosome. This, however, is a possibility the authors do not discuss.

Admittedly Burn and Gibbens recognise the need for family studies, but in their absence we are left with one more skeleton in an area littered with the bones of too many insufficiently tested hypotheses. To show by classroom example that disturbance of the sex ratio may be brought about by an Xlinked gene in the genotype of the mother or fetus or both is a long way from proving that such a mechanism is indeed at work in spina bifida and anencephaly. If the theory of Burn and Gibbens should turn out to be correct the practical importance would be that family studies could help to identify women at risk of producing a child with a neural tube defect. This speculation does not deserve to be taken seriously, however, until the necessary pedigree or experimental data have emerged.

1 Carter CO. Multifactorial inheritance revisited. In: Fraser FC, McKusick VA, Robinson R, eds. Congenital malformations. Amsterdam: Excerpta Medica, 1970:227-32.

2 Carter CO. Genetics of common single malformations. Br Med Bull 1976; 32:21-6.

3 Burn J, Gibbens D. May spina bifida result from an X-linked defect in a selective abortion mechanism ? F Med Genetics 1979;16:210-4.

- Roberts CJ, Lloyd S. Area differences in spontaneous abortion rates in South $\mathrm{W}$ ales and their relation to neural tube defect incidence. $\mathrm{Br} \mathrm{MedF}$ 1973 ;iv :20-2.

5 Carter CO. Clues to the aetiology of neural tube malformations. Develop Med Child Neurol. 1974 ;16:suppl 32, 3-15.

- Yen S, Macmahon B. Genetics of anencephaly and spina bifida? Lancet 1968;ii:623-6.

7 Leck I. The etiology of human malformations : insights from epidemiology. Teratology 1972;5:303-14. 